\title{
The good and the ugly: ANP antagonizes the deleterious effects of aldosterone in hypertensive cardiac remodeling
}

\author{
Hitoshi Nakagawal ${ }^{1 *}$, Katharina Völker ${ }^{1}$, Heike Oberwinkler ${ }^{1}$, Birgit Gaßner ${ }^{1}$, Charlotte Dienesch², \\ Sandra Umbenhauer ${ }^{2}$, Hideo A Baba ${ }^{3}$, Stefan Frantz ${ }^{2}$, Michaela Kuhn ${ }^{1}$ \\ From 6th International Conference on cGMP: Generators, Effectors and Therapeutic Implications \\ Erfurt, Germany. 28-30 June 2013
}

\section{Background}

Atrial natriuretic peptide (ANP), via its guanylyl cyclase A (GC-A) receptor and cyclic GMP formation, exerts cardiac antihypertrophic and antifibrotic actions. Conversely, aldosterone promotes pathological cardiac remodeling via the mineralocorticoid receptor (MR). To investigate whether local cardiac ANP/GC-A signaling counteracts the effects of aldosterone during experimental hypertensive cardiac remodeling.

\section{Results}

We studied the impact of the MR antagonist eplerenone $(100 \mathrm{mg} / \mathrm{kg} /$ day) on cardiac remodeling after transverse aortic constriction (TAC) in mice with conditional, cardiomyocyte-restricted deletion of GC-A (CM GC-A KO) [1] or cGMP-dependent protein kinase I (CM cGK I KO) [2] and respective controls ( $\mathrm{n}=10$ in each group). Left ventricular (LV) hypertrophy and interstitial fibrosis were significantly exacerbated in both CM GC-A KO and cGK I KO mice after TAC. These histological changes were accompanied by decreased LV SERCA2a expression, increased CTGF and LV dilatation together with contractile dysfunction. Eplerenone had no effect on systemic blood pressure but fully prevented these pressure-overload induced cardiac morphological, molecular and functional alterations in both CM GC-A KO and CM cGK I KO mice. However, eplerenone did not inhibit TACinduced MAPK ERK1/2 phosphorylation/activation, suggesting that the non-genomic effects of aldosterone are not involved in exacerbated hypertensive cardiac remodeling of the KO mice. Intriguingly, in transfected HEK

\footnotetext{
* Correspondence: nhitoshi@mub.biglobe.ne.jp

${ }^{1}$ Institute of Physiology, University of Würzburg, Germany

Full list of author information is available at the end of the article
}

293 cells, ANP inhibited the aldosterone-induced nuclear translocation of the MR.

\section{Conclusion}

ANP, via GC-A/cGMP/cGKI signaling in cardiac myocytes, attenuates hypertensive cardiac remodeling and dysfunction. These protective ANP effects seem to be mediated at least in part by counterregulation of the deleterious genomic (MR-mediated) cardiac actions of aldosterone.

\section{Acknowledgements \\ Supported by the comprehensive heart failure center (CHCF) in Würzburg. The CM CGKI KO mice were generated together with Dr. Franz Hofmann} and Dr. Robert Feil.

\section{Authors' details}

${ }^{1}$ Institute of Physiology, University of Würzburg, Germany. ${ }^{2}$ Department of Internal Medicine 1, University Hospital Würzburg, Germany. ${ }^{3}$ Department of Pathology and Neuropathology, University Hospital of Essen, University of Duisburg- Essen, Germany.

\section{Published: 29 August 2013}

\section{References}

1. Holtwick R, van Eickels M, Skryabin BV, Baba HA, Bubikat A, Begrow F, Schneider MD, Garbers DL, Kuhn M: Pressure-independent cardiac hypertrophy in mice with cardiomyocyte-restricted inactivation of the atrial natriuretic peptide receptor guanyl cyclase-A. J Clin Invest 2003, 111:1399-1407.

2. Frantz $\mathrm{S}$, Klaiber $M$, Baba HA, Oberwinkler $H$, Völker $K$, Gaßner B, Bayer $B$, Abeßer M, Schuh K, Feil R, Hofmann F, Kuhn M: Stress-dependent dilated cardiomyopathy in mice with cardiomyocyte-restricted inactivation of cyclic GMP-dependent protein kinase I. Eur Heart J 2013, 34:1233-1244.

\section{doi:10.1186/2050-6511-14-S1-P46}

Cite this article as: Nakagawa et al:: The good and the ugly: ANP antagonizes the deleterious effects of aldosterone in hypertensive cardiac remodeling. BMC Pharmacology and Toxicology 2013 14(Suppl 1): P46. 